\title{
A MEMÓRIA DE RAHUL
}

\author{
RAHUL'S MEMORY
}

Morganna Sousa Rocha $(\mathrm{UnB})^{1}$

\begin{abstract}
RESUMO: Este artigo busca problematizar e compreender a manifestação das memórias do narrador personagem Rahul, no último romance de Lygia Fagundes Telles intitulado As Horas Nuas. Para tal objetivo, seguimos na esteira fenomenológica de Paul Ricoeur e, por razões didáticas, decidimos discutir as memórias em três diferentes blocos, já que na narrativa as lembranças aparecem juntas e confusas. O desejo é compreender falhas e dúvidas da atividade rememorativa, além de delinear o que pode ser verdade ou imaginação, seguindo rastros discursivos e mnemônicos.
\end{abstract}

PALAVRAS-CHAVE: Memória. Imagem. Narrativa.

ABSTRACT: This article seeks, with the aid of Paul Ricoeur's phenomenology of recollection, to discuss and understand the manifestation of Rahul's memory. Rahul is a remarkable character in Lygia Fagundes Telles's latest novel entitled As Horas Nuas. For didactic reasons, the analysis is organised in three movements. The aim is to understand and to describe gaps and doubts in the recollecting activity, besides outlining what could be truth or imagination, by following discursive and mnemonical trails.

KEYWORDS: Memory. Image. Narrative.

Trata-se de compreender a memória de Rahul, curioso personagem da literatura contemporânea. Para efeito de um texto objetivo, o foco será na reminiscência e evocação de lembranças do personagem, apropriando-nos do máximo de informações existentes no romance para compreender sua longa e complexa memória.

O personagem é Rahul, gato de Rosa Ambrósio, no romance As Horas Nuas (1989). A narrativa se divide por três diferentes vozes, que nos oferecem três focos distintos e aparecem sem aviso prévio, levando-nos para diferentes tempos e problemas. Temos o gato, Rosa e um narrador em terceira pessoa com olhos sobre a terapeuta Ananta. O tempo do romance oscila entre dois passados distantes e um passado recente, embora este último manifeste-se mais em Rahul, o gato com memória.

Rahul, escrito desta maneira incomum, é o gato de uma atriz decadente e, como todo felino que se preze, é observador, temperamental e muito quieto. O incomum

\footnotetext{
${ }^{1}$ Mestra em literatura pela Universidade de Brasília, departamento de teorias literárias e literaturas. Pesquisadora da área de literatura brasileira e história. E-mail: morgannasrocha@hotmail.com
} 
deste chano narrador é a sua memória. Ao contrário do que afirma a ciência, segundo a qual os felinos têm memória de cerca de 16 horas, este gato lembra-se de sensações, acontecimentos e pessoas de tempos muito anteriores à sua vida de gato.

Dividimos a memória da maneira como ela se apresenta, em três partes. A vida presente de Rahul é sem novidades e tomada por solidão depois da morte de Gregório, esposo de Rosa Ambrósio. O gato, envolto pela solidão, vê-se constantemente tomado pelo passado, assaltado por suas lembranças e qualquer coisa no presente, cores, cheiros, vozes e imagens tornam-se gatilho e logo as lembranças passam a preencher seu tempo.

A narrativa do gato parece sempre acontecer no presente do indicativo, mesmo quando narra o passado, o que talvez nos seja dado pela visualidade bem concretizada na estilística do texto. A linguagem usada para narrar e descrever faz questão de presentificar visualmente o que é contado, fazendo com que tudo pareça presente, o que nos remete a Confissões de Agostinho, com seu presente em três dimensões: presente do passado, presente do futuro e presente do presente.

Sei com certeza que nós na maior parte das vezes, premeditamos as nossas ações futuras, e essa premeditação é presente, ao passo que a ação premeditada ainda não existe, porque é futura. Quando empreendermos e começarmos a realizar o que premeditamos, então esta ação existirá, porque já não é futura, mas presente. De qualquer modo que suceda este pressentimento oculto das coisas futuras, não podemos ver senão o que possui existência. Ora o que já existe não é futuro, mas presente. Por conseguinte, quando se diz que se vêem os acontecimentos futuros, não se vêem os próprios acontecimentos ainda inexistentes - isto é, os fatos futuros - mas sim as suas causas, ou talvez os seus prognósticos já dotados de existência. Portanto, com relação aos que os vêem, esses acontecimentos não são futuros, mas sim presentes. (AGOSTINHO, 2012, p.326)

Sempre que conduzidos em narrativa por narrador em primeira pessoa, tudo o que vemos, ouvimos ou entendemos está indiscutivelmente associado à visão do narrador, que funciona como a lente de uma câmera. Pode fechar em ângulos, enquadrar e revelar, como faz o narrador ao fim de cada sentença. Se observarmos a cena individualmente, veremos que ela é composta de quadros que, vistos isolados, possuem uma temporalidade à parte do tempo de toda a cena. É como se os três presentes que cita Agostinho fossem quadro a quadro de uma mesma cena que é componente do imediato presente narrado, ou seja, como se cada passado, de algum modo, fosse uma parte do presente de Rahul. 
A memória e a narrativa de Rahul oscila entre presente e passado, em muitos momentos entendemos como presente o que na verdade se deu há algumas centenas de anos atrás. A sensação que permanece é que estamos sempre no passado do presente mesmo que os verbos estejam no presente do indicativo. Este recurso de transporte para o presente imediato, com intuito de narrar o acontecimento passado, é marca registrada nos textos de Lygia Fagundes Telles. Do ponto de vista fenomenológico, isso indica uma constante tentativa de dar validade e certeza à memória. No que tange ao narrar, é colocar o leitor sem intermédio do tempo diante do acontecimento, presentificar o leitor na lembrança. Descrever minuciosamente coisas e pessoas, sons, cheiros e cores, oferecer mais aos nossos sentidos é técnica que acaba por criar um efeito visual sobre o texto.

Rahul é dono de uma narrativa detalhada, rasteira em sua perspectiva de gato, incerta em sua perspectiva humana. Gatos possuem o hábito de escolher esconderijos variados pela casa, como se em cada cômodo fosse preciso um canto seguro de abrigo e de observação. Estes cantos são estratégicos, em lugares baixos ou altos e precisam oferecer segurança, tranquila observação do ambiente e seus habitantes. Nosso gato narrador, para fugir do contato humano, prefere por abrigo lugares baixos, entre plantas, debaixo de móveis apertados ou na estante esquecida de sapatos velhos. Sua narrativa sempre segue de debaixo para cima, pés e pernas estão sempre no primeiro quadro da cena, para só então subir gradativamente até alcançar o corpo por completo, a isto chamamos de narrativa rasteira, no sentido literal. Se voltarmos a imagem da câmera nos lembraremos que este é um recurso comum para sugerir a baixa estatura ou o estado emocional daquele que vê, em As Horas Nuas daquele que narra.

Na sua estilística narrativa, o romance, que a princípio parece bem casual, mostra um refinado trato linguístico e filosófico, além da visualidade cinematográfica. Esses recursos estão empregados em linguagem simples, quase direta, nota importante em se tratando de romances memorialísticos, pois a linguagem bem resolvida é a única maneira eficiente de tentar presentificar, em texto, o passado. $\mathrm{O}$ trecho de Agostinho diz que não importa se tratamos do futuro ou passado, ambos precisam da mediação do presente para existir. É assim que se comporta Rahul presentificando seus passados:

Amanhece. Cheiro de mel e leite de cabra. A imagem do menino passa por mim mais ligeira do que uma sombra. Cabelos escuros. Túnica branca. Sigo atrás pelo caminho que já conheço através de um furo no tempo, olho por esse furo e vejo grandes árvores. Um rio pardacento. O menino mergulha nessas águas. Ouço com alegria o ruído vigoroso das minhas braçadas, estou nu na correnteza. O bosque. 
Entrei no rio menino e dele saio um jovem, mas esse prodígio não me abala, só me ocupa um pensamento o que vem pela frente?... (TELLES, 1999, p.25)

Visualidade ímpar e, novamente, a imagem da câmera nos aparece. Nosso personagem encontra um furo no tempo, espia e com ele seguimos para, de repente, emergimos do rio. O gato saiu do papel de observador de um passado para o de observador no presente. Esta potencialidade só a narrativa oferece, não há uma maneira de comunicação que transmita vivência, vivido e experiência tão eficientemente. O discurso, especialmente aquele em primeira pessoa, potencializa lembranças e imagens. Com Ricoeur, em A memória, História e Esquecimento, descobrimos que a lembrança, enquanto aquilo que nos acontece, pode vir como imagem, ou seja, realização visual da lembrança. Em muitos momentos, o gato Rahul vê imagens e pessoas, mas não tem certeza de que sabe quem são; se memória ou produto da imaginação. A incerteza destas imagens, dissociadas de qualquer rastro ou vestígio do passado, colocam o caráter memorialístico da narrativa sempre sob suspeita. As imagens podem ser colagens trazidas pela imaginação, ou ainda, segundo o folclore popular, podem ser não imagens, mas figuras, fantasmas que somente gatos pode ver.

Lembrança e imagem são conceitos que se voltam sobre eles mesmos. O que procura Ricoeur é diminuir a confusão feita entre os dois termos que se tornaram quase sinônimos. A lembrança não é uma imagem, ela pode residir em uma imagem, mas não pode ser confundida com esta. Quando Rahul vê vultos, figuras, ou mesmo imagens em seus sonhos, são acontecimentos solitários, não há em sua memória nenhuma lembrança em relação aquilo que vê. Ou seja, existe uma imagem, mas não uma lembrança, se me lembro do cheiro do café fresco de minha avó, lembro do cheiro, esta memória não está necessariamente ligada a imagem do café, mas antes à intuição: minha avó passou café.

Ricoeur, no livro citado, pergunta-se: “é a lembrança uma espécie de imagem? E em caso afirmativo qual?”. Arriscamos dizer que a lembrança se situa no caráter intuitivo da imagem. Paul Ricoeur é fenomenólogo, o que significa entre muitas coisas, entender que todas as coisas possuem um caráter intuitivo, ou seja, eu posso ver, imaginar, intuir uma coisa sem que eu possa vê-la fisicamente. Imagem é aquilo que eu intuo, vejo ou imagino. É nesta última palavra que acreditamos encontrar a principal diferença.

Segundo Ricoeur, temos dois tipos de imagem. A primeira, do alemão Bild, está pautada na memória de minhas experiências, não são completamente imaginadas. No romance As meninas, a personagem Lia passeia por São Paulo e comenta que a cidade cheirava a pêssego. Ora, mesmo que seja somente um texto em papel é possível 
experienciar a fruta, porque em algum momento eu comi pêssego e o cheiro penetrou minhas narinas e ali fez marca, mas, ainda que esta experiência não tenha feito marca, ainda que nunca tenha provado o pêssego, minha experiência com frutas me indicará um caminho para compreensão da frase. A outra imagem a qual Ricoeur se refere é Phantasie, uma imagem que pode estar totalmente firmada no universo da irrealidade. Por exemplo, quando Rahul é puxado pelo rabo, nossa imagem é Bild, pois conseguimos ver a cena que ele conta com raiva, mas quando narra a cena do puxão, enquanto bebe leite com a língua e o leite evoca suas memórias de humano, nossa criação de imagem é Phantasie e nosso juízo de realidade está completamente suspenso, mas sem que esta suspensão indique descrédito, somos, antes, subtraídos pela realidade literária/imaginária.

Parafraseando Ricoeur, a imagem se produz no terreno do imaginário, é a sedução, encantamento destinado a fazer aparecer o objeto em que estamos pensando ou desejando, de modo a possuí-lo. Por isto o caráter de dúvida quando a imagem de uma lembrança nos acontece. Imaginar não é lembrar. A lembrança, à medida que se atualiza, passa a viver em uma imagem, mas não acontece o contrário, e a imagem só me levará de volta para o passado se ela vem realmente do passado.

Encontramos no romance marcas que indicam separação entre lembrança e imagem. Já lembramos aqui as visões do chano narrador e nossa incerteza quanto ao caráter de lembrança destas figuras. Notamos que a lembrança pode viver em uma imagem, mas esta não vive na lembrança, a imagem está sempre em transformação, à medida que Rahul consegue ir mais fundo nas suas reminiscências, a imagem ganha mais elementos. O lembrado não precisa, mas apoia-se na imagem, que é a presentificação do lembrado.

A imagem está ligada ao campo da imaginação e por isto as imagens nas quais moram nossas lembranças não costumam ser fiéis. Se temos uma lembrança meio confusa ou duvidosa, nossa imaginação vai, sem autorização, montar, criar, preencher lacunas, por isso, se uma imagem nos acontece com frequência, a cada retorno ela estará mais nítida.

No segundo capítulo, encontramos Rahul olhando seu eu no passado, trecho já transcrito, em rememoração longa e rica em detalhes. Vê-se correndo e mergulhando no rio, mas quando a pintura da rememoração começa a desmanchar na realidade do presente, dá-se, para nossa surpresa, a delicada e rápida suspensão da realidade: “Apertei meu peito inquieto com a palma da mão assim como faço agora. A diferença é que já não 
tenho a mão à altura do gesto, mas uma pata. Veludosa. As unhas bem aparadas para não puxar o fio dos tapetes de Rosa Ambrósio.” (TELLES, 1999, p.27).

Ao abrirmos um romance, fazemos um acordo silencioso com a imaginação: isto é ficção. O fato de ser um felino a narrar não diminui o caráter de verossimilhança, pelo contrário, aquilo que é estranhamento no início, logo se torna empatia, quando reconhecemos nele nossas experiências, medos, afetos e memórias. A verossimilhança que poderia simplesmente não existir, por tratar-se de ficção, é restaurada à medida que avançamos sobre a narrativa e quando nos aproximamos do final passamos até mesmo a reconhecer em Rahul feições mais humanas do que em outros personagens.

Como dito de início, dividimos a memória de Rahul em dois passados distantes e um passado recente, analisemos cada um. O primeiro é dado em tempo antiquíssimo, no qual era um jovem de túnica branca e em espaços de arquitetura romana. A lembrança da casa e do acontecimento vem perfeita, os móveis, as roupas, os homens e embora não seja possível precisar datas, acreditamos tratar-se do ainda império romano. “enveredo por uma praça rodeada de colunatas” (...) "atento ao homem de toga púrpura falando” (...) “A minha casa. O átrio. O peristilo e o jardim todo florido”. (...) “a mesa com os pés de bronze imitando patas de leão”. (...) “O som suavíssimo de uma cítara” (...) “mais próximo o ruído das suas sandálias no mármore polido”.

A maior parte desta lembrança trata de um ato sexual entre o gato, quando humano, e um homem aparentemente pouco mais velho. Lembramos que Rahul se viu na pele deste jovem, mas somente depois de emergir do rio, aconteceu o reconhecimento. Esta é a memória mais antiga de Rahul. A lembrança aconteceu e a imaginação foi completando-a. Seja por mneme, evocação, ou por procura, anamnesis. A riqueza de detalhes até nos sons mostra como o levantamento desta lembrança foi perfeito, mas não completo. Enquanto o jovem - Rahul em sua lembrança mais antiga - estava na praça, o homem de toga conversava com dois outros jovens em uma língua familiar, mas que ele, Rahul, não fora capaz de compreender. No entanto, ele reconheceu imediatamente como sua a casa romana. Lembrança incompleta, em que faltam pedaços; o reconhecimento se dá em trechos específicos, aparentemente mais revisitados por anamneses.

Nesta memória tão antiga vemos aquilo que Ricoeur chama de memória impedida. Não sabemos a razão, mas sempre que o gato faz esforços e concentra-se nesta rememoração, é abruptamente repelido por um entrave desconhecido. A memória impedida é, antes, uma memória enferma, bloqueada pelo inconsciente para sobrevivência e continuidade, uma natural tentativa de cura por parte da memória ferida. 
Conceito facilmente compreendido ao estudar relatos de sobreviventes de guerras, torturas ou outros acontecimentos traumáticos. Na particular situação de Rahul é possível reconhecer o bloqueio, mas não diagnosticá-lo ou mesmo conjecturar. Da perspectiva de Ricoeur e da própria psicanálise, a maneira abrupta e gratuita com a qual o gato é impedido de prosseguir na rememoração, é característica de mecanismos de proteção, pois se dão na procura voluntária, pelos trechos apagados, ou mesmo em seus sonhos.

O grito. Pelo funil desse grito escapei do meu corpo que prosseguia livre no ritmo de gozo, mas agora sem mim. Fiquei aturdido, sem entender, mas o que estava acontecendo? Quando decidi me recuperar foi como se entre o meu corpo e entre mim mesmo se levantasse uma parede invisível, bati nesse vidro com os punhos desesperados (...) ainda me via, mas não me tinha, fui excluído para virar um pasmado expectador do corpo perdido. (TELLES, 1999, p.27)

Rahul não possui memórias, é possuído por elas. Em momentos de evocação, em que a lembrança simplesmente acontece, tendemos a reconhecer na evocação um caráter de verdade. No entanto, ao final da rememoração, do ato descritivo do narrador, já não há certeza e o gato parece ser tomado por memórias além, tempos e lugares desconhecidos por ele próprio até o momento. O bichano faz um uma espécie de apanhado de suas memórias passadas e afirma que vivera uma breve vida como atleta, o que parecia ser continuidade da vida do jovem romano em uma corrida de revezamento, torna-se uma overdose de heroína em um hospital, cercado por aparelhos, médicos e um bilhete suicida. Paisagens e rostos se misturam, os momentos de certeza do início da narrativa vão diluindo-se à medida que o personagem reflete sobre sua própria atividade rememorativa.

Enquanto afirma ser lembrança aquilo que lhe vem, Rahul duvida e culpa a imaginação: “Ainda a invenção? Simples necessidade de compensar a forma atual através da fantasia - será isso?” (TELLES, p.61). A segunda memória de Rahul nos faz perceber o quanto sua antiga humanidade está sempre pedindo lugar, prova disto é quando Rahul faz sua higiene pessoal, o momento de limpar seu sexo o deixa enojado, não somente de ter de fazê-lo com a língua, mas de querer fazê-lo. Bild e Phantasie voltam à cena. A imagem do gato lambendo-se é ordinária Bild, mas a imagem do animal realizando o gesto e reconhecendo-o como feio é algo é extraordinária, ou seja, Phantasie. Ricoeur usa estes termos inspirado em Edmundo Husserl, pai da fenomenologia, a quem Ricoeur dedicou grande parte de sua vida intelectual. Husserl entende Bild como presentificações que descrevem alguma coisa indiretamente, fotografias, quadros, estátuas. Quando fala 
em Phantasie Husserl, pensa no universo dos contos de fadas, nas lendas, trata-se de ficção.

As lembranças referentes à casa das venezianas verdes que compõem esta memória não são fragmentos, como na primeira, mas sim completas e de uma memória longa. Com lacunas sim, mas com riqueza de detalhes, diálogos, cheiros, quase uma memória completa de sua infância como menino. A narrativa desta é sempre referida como a 'casa das venezianas' e é narrada de duas diferentes maneiras. A primeira é quando o gato se coloca na posição de menino, o eu presente no passado: "Na noite antiga ouço essa irmã dizer baixinho que mamãe tinha piorado, precisa com urgência de um tratamento sério, hoje nem me reconheceu!” (TELLES, 1969, p.61). A segunda é quando o gato se coloca na posição de observador, o eu do presente observador do passado: "Ele não sabe, mas se sente vagamente ameaçado no imenso casarão e então se esconde nos cantos, entra nos armários, nas arcas. Foge às vezes para o pomar onde a irmã ou a agregada vai buscá-lo.” (TELLES, 1989, p.63).

A esta memória também não é possível datar, às vezes, parece ser algum momento no final do século XIX, devido às roupas, penteados ou à antiga máquina fotográfica, mas não há como precisar. As lembranças que dizem respeito à casa das venezianas verdes não parecem dúbias, são imagens certeiras, a mneme aconteceu há muito tempo, o narrado é uma lembrança revisitada, presentificação de um passado vivido e já muitas vezes presentificado. Nesta memória é menino pequeno, talvez uns seis ou sete anos, sabe que seu pai morrera recentemente, mas não se lembra do pai, do funeral ou qualquer coisa a respeito. Cogitamos datar a memória a partir do antigo costume de afastar a criança de casa quando do falecimento de alguém. Sabemos que tinha uma irmã estrábica, muito baixa e de cabeça grande, mas que parecia muito bonita de cabelos soltos molhados e, sob o sol, uma mãe que enlouquecera depois da morte do esposo e a agregada Marta, que cuidava do menino.

Todos os acontecimentos narrados pertinentes à casa das venezianas têm ar de familiaridade, não provocam estranhamento de sensações, pessoas e espaços. Bem diferente da memória romana, aqui ele sente saudades. Um importante registro rememorativo é dado nas descrições de espaço, móveis, pessoas e a própria casa tem visualmente dimensões maiores, tudo apontava para sua solidão infantil em um mundo de coisas e pessoas grandes. O menino não brincava com outras crianças e a solidão habituara-o à observação, Rahul lembra-se das mulheres no serviço doméstico, das grandes janelas que a irmã abria, tudo é descrito sem dúvida, sem hesitação, com a 
mansidão de quem aproveita cada palavra, marcas de uma reminiscência prazerosa. O caráter visual desta parte da narrativa é bastante cinematográfico, os olhos do gato sob seu antigo eu diminuem dúvidas e lacunas, dá-nos a sensação de duas câmeras na mesma cena, a impressão de dois diferentes olhares sobre o mesmo objeto, ainda que de uma mesma lente, Rahul.

A posição de observador do eu presente no passado dá ao gato comodidade e distância necessárias para entender acontecimentos e antigos sentimentos. Olho-câmera, é como se o furo no tempo pelo qual Rahul penetrou estivesse novamente à disposição. Possuído pelo tempo, sua antiga humanidade pede lugar. A memória que o possui é quem decide que ângulo, a que imagem poderá o gato ter acesso, nos momentos em que é puxado de volta pelo buraco, quando é separado do seu corpo anterior, sentimos a agonia de uma memória impedida.

O impedimento é causado por alguma espécie de trauma que bloqueia a continuidade da reminiscência, mas que não conseguimos identificar em nenhuma das lembranças pelo gato oferecidas. Talvez a primeira memória esteja incompleta porque é antiga demais, talvez suas memórias de menino tenham sido preservadas porque eram as que inconscientemente mais queria, ou mesmo porque nesta segunda memória a imaginação seja o elemento decisivo, preenchendo as lacunas abertas pelo tempo, ou seja, manipulando-a, ainda que sem querer.

Se esta é uma das memórias preferidas do chano narrador, ela está sempre retornando e ele remodelando e colorindo-a, a cada presentificação, lembranças e imagens (Bild) vão surgindo. A imaginação é ativada somente pelo querer sem que a consciência seja avisada e a memória frágil seja capaz de se defender do abuso da imaginação. Lembramos que isto é apenas uma hipótese, estamos problematizando o que queremos entender, porque é esta a memória mais completa de Rahul. Poderia ser esta uma memória perfeita, a presentificação perfeita mesmo que sem continuidade, de seu eu presente no passado? Ou não seria memória nenhuma, seria somente imaginação para preencher uma vazia vida de gato doméstico?

A casa das venezianas verdes sugere uma memória manipulada a qual Ricoeur vinculará imaginação e identidade. Não é a memória abusiva deste gato um indício de sua procura ou insatisfação com sua identidade? Segundo o hermeneuta a memória é manipulada quando mobilizada para a criação e reivindicação de uma identidade. Os resultados desta mobilização podem ser: excesso de memória, caso de Rahul, insuficiência de memória, abuso de esquecimento. "Pois bem, é na problemática 
da identidade que se deve agora buscar a causa de fragilidade da memória assim manipulada.” (Ricoeur, 2007, p.95). A fragilidade da identidade consiste na fragilidade das respostas que damos a perguntas como ‘quem sou eu?’, 'O que sou eu?’, 'quem?’. Esta fragilidade possui três causas que discutiremos individualmente.

A primeira é sua relação com o tempo e a dificuldade de lidar com ele justificando o recurso da memória, enquanto componente temporal da identidade. "Ora, a relação com o tempo cria dificuldades em razão do caráter ambíguo da noção do mesmo, implícita na do idêntico. O que significa permanecer o mesmo através do tempo?” (Ricoeur, 2007, p.94).

A segunda trata-se da fragilidade identitária do relacionamento, confronto com o outro que passa a ser percebido como uma ameaça para a própria identidade. Como se a identidade fosse suficientemente frágil para ser alterada pela convivência com o diferente, de não conseguir inscrever sua identidade no viver juntos. "São mesmo as humilhações, ataques reais ou imaginários à autoestima, sob golpes da alteridade mal tolerada, que fazem a relação que o mesmo mantém com o outro mudar da acolhida à rejeição, à exclusão.” (Ricoeur, 2007, p.95).

A terceira é a herança da violência fundadora. Embora possua um caráter menos individual, a justificativa desta memória está pautada na representação da memória coletiva. A identidade brasileira, por exemplo, é dada pela miscigenação da qual somos fruto. A identidade indígena precisava ser suplantada em função da portuguesa, a violência com a qual isto aconteceu é celebrada no mês de abril como descobrimento/chegada dos estrangeiros ao Brasil, mesmo que saibamos o que esta verdadeiramente representou. A celebração de um lado representa a humilhação do outro. A fragilidade está na forma, violenta ou sutil, com que a identidade é oprimida em função do outro, seja na colonização portuguesa, ou na atual imposição da magreza.

A fragilidade da identidade do gato revela sua fragilidade no tempo: Rahul viveu muito, possuir memórias humanas em um corpo de gato o confunde sobremaneira, não ser dono de suas próprias lembranças o torna incapaz de responder perguntas como quem ou o que sou eu. No entanto, ainda que as responda, outra perguntas serão ainda levantadas, "se sou um gato por que me lembro de ser criança de cachos na casa das venezianas verdes?” “Quem era então o jovem romano, ou o que suicidou-se?”. É o desejo de resposta que mobiliza a memória de Rahul para estas perguntas. Nelas encontraria uma identidade. A mobilização, entretanto, provoca o excesso de memória, enquanto o abuso, 
por sua vez, mobiliza também a imaginação que é ativada em toda anamnesis sem que aquele que rememora perceba.

É sob o signo da associação de idéias que está situada essa espécie de curtocircuito entre memória e imaginação: se essas duas afecções estão ligadas por contigüidade, evocar uma - portanto imaginar- é evocar a outra, portanto, lembrar-se dela. Assim, a memória, reduzida à rememoração, opera na esteira da imaginação. (RICOEUR, 2007, p.25)

É em razão da associação entre imaginação e memória, no trabalho de mobilização desta última, para suportar a fragilidade de sua identidade, que a casa das venezianas verdes é uma lembrança mais longa, quase completa. O caráter afetivo desta memória está na figura da mãe que enlouquecera e do pai, do qual nem Rahul ou o menino conseguem lembrar, a afetuosidade de uma lembrança também influencia em sua constante presentificação. A lembrança não é estática, a cada presentificação um novo elemento aparece, seja trazido do passado ou criado pela imaginação. O que separa imaginação de memória não pode jamais ser distinguido. $\mathrm{O}$ acontecimento passado foi único, impossível de ser vivido novamente, tudo que eu fizer para presentificá-lo é mediado pela linguagem e esta possui um caráter imaginativo.

A última memória é de passado recente, no qual Gregório ainda vivia. Esta é perfeita. Quanto ao que viu, viveu e que interessa nos contar, não há dúvidas. Suas lembranças não seguem orientação cronológica e como o estilo da narrativa é de prosa reflexiva não há surpresas quando as reminiscências se colocam entre os acontecimentos do presente. Rahul fora encontrado na rua e chega à casa de Rosa Ambrósio no bolso de um casaco. Neste tempo, a mulher ainda atuava e era casada com o astrônomo Gregório, então preso pelo regime militar. Cordélia, filha do casal, ainda morava com os pais, embora já fosse adulta. O apartamento ficava no bairro dos Jardins. Haviam dois empregados, Dionísia, Diú, que cuidava de todo o serviço doméstico, e Diogo assessor e amante de Rosa.

Ao narrar, Rahul presentifica acontecimentos passados sem nos avisar, nosso olhar acompanha o do narrador em primeira pessoa, nossa certeza é de que o acontecimento está em desenvolvimento. Presentificar o passado é o único jeito de entendê-lo, trata-se de uma memória que não deu lugar ao esquecimento, por isto a narração parece ser imediata aos acontecimentos. 
Mencionamos a narrativa rasteira de felino e a visualidade única que estes momentos nos oferecem. No que diz respeito ao processo de rememoração, esta memória não tem muito a nos oferecer, trata-se de passado recente que não foi submetido ao trato da imaginação. Por esta razão, este passado tão completo e tão presente oferece-nos duas informações. A primeira, já citada, é de que o passado recente independe da mobilização intensa da memória, a segunda é que o caráter afetivo da lembrança impõe o seu desejo sobre a memória. Esta última pode parecer arbitrária por sabermos da impossibilidade de controle da memória, mas não raro a memória trabalha a nosso favor. Quando escolhemos momentos e os rememoramos com frequência, ou seja, o presentificamos para aproximarnos o máximo possível do presente no passado, o caráter afetivo mobiliza a memória a nosso favor e o exercício de rememoração contribui para a continuidade desta memória.

Nesta terceira e última memória, a presentificação é de toda afetiva, o gato amava muito a Gregório e sua morte deixou um vazio que procura preencher com a presentificação do tempo antes de sua morte. Toda esta parte da narrativa acontece no presente, para depois sabermos de que fora há três anos. Já não existe mais Gregório ou Diogo, a casa é agora habitada só por mulheres como fora na segunda memória. A narrativa rasteira traz visualidade cinematográfica e progressão da imagem, que contribuem com a presentificação do passado e para a verossimilhança do narrado. Uma dessas marcas de câmera é um recurso comum no cinema chamado contra-plongè que coloca a câmera em diagonal, de debaixo para cima, este recurso avulta o objeto/imagem diante da câmera e denota a miudeza do observador ante o poder/grandeza do observado. O contra-plongè em As Horas Nuas são os olhos de Rahul, que seguem com exatidão a descrição acima. Para olhar para cima por longo tempo, o gato precisa se colocar sob as patas traseiras, apoiar-se nas dianteiras que continuam retas e inclinar a cabeça em diagonal. Com exatidão, os olhos de Rahul se tornam a câmera que nos apresenta narrativa e personagens, muitas vezes, atravessando o furo no tempo.

Nesta memória sempre que se refere a Diogo, que odiava, Gregório que amava e Dionísia de quem gosta, o chano olha para cima, as figuras são grandes e potentes. Diogo é grande jovem e forte, pode machucar Rahul como já o fez. A grandeza de Gregório é admiração, respeito, com contínua associação do pai que perdera na casa das venezianas verdes. Embora Gregório o pegasse no colo e brincasse, as descrições feitas do astrônomo são sempre visualmente grandes, como se Rahul sempre o olhasse do chão e de longe. A figura de Dionísia é menos respeitosa, mas demonstra carinho, o gato gostava de refletir sobre ela, suas varizes grossas o faziam pensar na sua infelicidade de 
ter nascido negra e mulher. A última figura, Rosa Ambrósio, ocupa visualmente espaço muito diferente.

Rosa Ambrósio e seu gato estão quase sempre no mesmo plano. A princípio grande como os outros, mas sua decadência acaba por colocá-la no mesmo nível descendente no qual ele se encontra. A personagem está sempre bêbada caída em algum canto da casa, deitada na banheira, no sofá da sala, no chão do quarto, também perdida em suas reminiscências. Rahul e Rosa Ambrósio compartilham do mesmo nível de degradação, ela infeliz com o abandono causado pela velhice e ele na sua condição de bicho, sem possibilidade de ação. “A única vantagem do bicho sobre o homem é a inconsciência da morte e da morte eu estou consciente” (TELLES, 1989, p.129). Rahul preocupa-se com Rosa, depois da morte de Gregório e da ida de Diogo, sua dona está completamente abandonada, nem banho toma. Como gato nada pode fazer e torce pela volta de Diogo, mas o gato está sempre na mesma condição que o impede de fazer qualquer coisa para proteger Rosa. O narrador caminha pelo corpo da dona caída no chão. "Respondo caminhando ao longo das suas coxas. Chego até a meia lua do ventre macio. Tiro as unhas e arranho de leve esse ventre, precisa parar Rosa Ambrósio. Parar ouviu isso? Assim você morre, precisa parar! fico repetindo”. (TELLES, 1999, p. 95)

Marcado por solidão e afetuosidade as lembranças recentes parecem intactas, a dubiedade reside nas figuras que aparecem a Rahul, fantasmas ou reminiscências. Destas imagens sem data e sem conexão, a única que sabemos ser lembrança é Gregório que apareceu algumas vezes depois de morto. Nas visitas que fazia a seu escritório, Gregório permanecia em atividades a qual se dedicara enquanto vivo, como se nada tivesse acontecido. Quanto às outras imagens, Rahul não consegue entender quem são; se pertencem a outras memórias. As visões se comportam como lembranças que se submetem ao esquecimento, imagem completa que o tempo borra até apagar. Todas as visões ou imagem de lembranças que apareciam com frequência vão sumindo a cada visita, as pessoas se tornam contornos, mas que continuam a ler ou olhar o céu, como se continuassem a existir, para estas figuras a existência parece um hábito. O caráter fugidio da lembrança enquanto componente de memória é que dá à memória este caráter impreciso, aquilo em que não se pode confiar completamente, no entanto, é tudo que temos.

O excesso de memória em Rahul não é único na obra de Lygia Fagundes Telles, a escritora paulista faz do tema matéria fecunda, a reminiscência é sempre curiosa e potente. Não se trata somente de lembrar, para suas narrativas, o passado alimenta o 
presente, pessoas e acontecimentos não ficam perdidos, pois estão eternamente em atividade, revividos ou mesmo presentificados como faz o gato narrador. A fascinação sobre o tema na obra lygiana reflete, em muito, nossa obsessão de controle sobre toda a experiência. Uma vez vivido, o passado deixa de nos pertencer. A história de Rahul, ou mesmo episódios da infância e adolescência de Lygia Fagundes Telles que se tornarem contos, deixam de pertencer a seus narradores e passam a pertencer-nos, seja este passado lido ou fisicamente experienciado, não há controle sobre nossa memória, nem mesmo sobre a atividade de rememorar, a linha que separa impedimento, lembrança e imaginação é delicada, tênue, fina como pelo de gato.

\section{Referências}

AGOSTINHO, Santo. Confissões. Trad.: Frederico Ozanam Pessoa de Barros. Rio de Janeiro: Nova Fronteira, 2009.

CANDIDO, Antonio. et al (Org.). A personagem de ficção. 12. ed. São Paulo: Editora perspectiva, 2011.

RICOEUR, Paul. A memória, A história, e O esquecimento. Trad.: Alain François. Campinas: Editora Unicamp, 2007.

TELLES, Lygia Fagundes. As Horas Nuas. Rio de Janeiro: Editora Rocco, 1999.

As Meninas. São Paulo: Editora Companhia das letras, 2009.

TIETZMANN, Vera Maria. Dispersos \& inéditos: estudos sobre Lygia Fagundes Telles. Goiânia: Cânone editorial, 2009. 